\title{
Erratum to: A new resource of single nucleotide polymorphisms in the Japanese eel Anguilla japonica derived from restriction site-associated DNA
}

\author{
Masashi Sekino $^{1}$ - Reiichiro Nakamichi ${ }^{1}$ - Yuki Iwasaki ${ }^{1}$ Akifumi S. Tanabe ${ }^{1}$. \\ Atushi Fujiwara $^{1} \cdot$ Motoshige Yasuike $^{1} \cdot$ Manabu Shiraishi $^{2} \cdot$ Kenji Saitoh $^{1}$
}

Published online: 4 August 2016

(C) The Ichthyological Society of Japan 2016

\section{Erratum to: Ichthyol Res}

DOI 10.1007/s10228-016-0518-7

The original publication of this article contains an erroneous description, which is corrected as stated below.

In the first paragraph of "Results", the fourth sentence reads,

"A preliminary analysis using our own perl script found 37,952 positions of $\operatorname{SbfI}$ recognition sites in the reference genome ... 79,836 SbfI-based RAD loci in the A. japonica genome (twice the number of SbfI recognition sites)". However, the number of SbfI recognition sites in the reference genome should be 39,918 .

The online version of the original article can be found under doi:10.1007/s10228-016-0518-7.

Masashi Sekino

sekino@affrc.go.jp

1 Research Center for Bioinformatics and Biosciences, National Research Institute of Fisheries Science, Japan Fisheries Research and Education Agency, 2-12-4 Fuku-ura,

Kanazawa, Yokohama, Kanagawa 2368648, Japan

2 Marino-Forum 21, 1-5-2 Hagoromo bldg., Hatchobori, Chuoku, Tokyo 1040032, Japan 